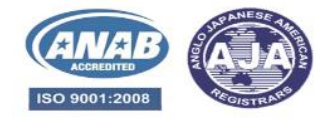

Sohag Medical Journal
Faculty of Medicine

\title{
Clinical Variability and Treatment Outcomes of Pediatric Esotropia at Sohag University Hospital
}

\author{
Ahmad Mostafa Abdallah, Amin Abuali Hassan. \\ Department of Ophthalmology, Sohag Faculty of Medicine, Sohag University
}

\begin{abstract}
Purpose: To evaluate the clinical features and treatment outcomes of convergent squint (esotropia) among children at Sohag University Hospital.

Methods: A prospective, case series, interventional study was conducted to evaluate esotropia among children presented to the strabismus outpatient clinic at Sohag University Hospital, in the period between April $1^{\text {st }}, 2018$ and December $31^{\text {th }}, 2018$; with a follow-up period of 12 months. A standard protocol for examination was followed for all patients including history, visual acuity, slit lamp /biomicroscopy, fundus examination, ocular motility, cover test, ocular deviation and cycloplegic refraction. Children with esotropia in this study were classified into 3 main groups, congenital (infantile) esotropia, accommodative esotropia and non-accommodative esotropia.

Results: A total of 52 children with non-paralytic (concomitant) esotropia were included; $27(51.9 \%)$ were males \& $25(48.1 \%)$ were females. There were $23(44.2 \%)$ patients with congenital (infantile) esotropia, $19(36.5 \%)$ patients with accommodative esotropia, and 10 (19.2\%) patients with non-accommodative esotropia. Successful (favorable) outcome was seen in $18(78.2 \%$ ) cases of congenital (infantile) esotropia,19(100\%) cases of accommodative esotropia, and $9(90 \%)$ cases of non-accommodative esotropia.

Conclusion: Pediatric esotropia can present at birth, during the first year of life, or acquired during early childhood. Treatment should be initiated as early as possible to achieve binocularity, improve visual outcome, and prevent psychosocial effects.
\end{abstract}

Keywords: Strabismus, esotropia, concomitant, accommodative, outcome.

\section{Introduction}

Strabismus (or squint) is a common presenting ocular disorder at ophthalmology outpatient clinics, with a worldwide incidence varying from $3 \%$ to $5 \%$. Many studies were conducted in the field of strabismus including those evaluated the prevalence, types, and treatment outcomes. ${ }^{1-7}$

Pediatric strabismus causes cosmetics, visual, and psycho-social problems affecting all qualities of life. Abnormal binocular function usually develops if strabismus appears early in life and untreated before visual maturity, resulting in amblyopia, suppression and abnormal retinal correspondence. Therefore, treatment of strabismus should be initiated as early as possible to achieve binocular single vision, improve visual outcome, and prevent the resulting bad psycho-social effects..$^{8,9}$

Management of pediatric strabismus involves careful preoperative assessment, treatment of refractive errors with 
glasses, prisms, or orthoptic exercises, and treatment of amblyopia. However, the majority of these cases require eye muscle surgery which is usually indicated to correct the eye position in primary gaze, and improve the range of binocular single vision. ${ }^{10,11}$

Few studies were conducted on pediatric strabismus in our locality. Therefore, this study was carried out to evaluate the clinical types, clinical features, and treatment outcomes of esotropia among child-ren presented to the strabismus clinic at Sohag University Hospital.

\section{Patients and methods}

A prospective, case series, interventional study was conducted to evaluate children presented to the strabismus outpatient clinic at Sohag University Hospital with esotropia, in the period between April $1^{\text {st }}$, 2018 and December $31^{\text {th }}$, 2018; with a follow-up period of 12 months. Inclusion criteria included patients aged $\leq 12$ years, presented with non-paralytic (concomitant) esotropia which was not associated with ocular pathology, nor with the neurological disorder. Patients with paralytic esotropia, ocular pathology, esotropia associated with neurological dysfunction, a history of previous strabismus surgery, or a postoperative follow-up period of fewer than 12 months were excluded from the study. The study was done in accordance with the Helsinki Declaration Principles, after obtaining the approval of the medical ethics committee at Sohag Faculty of Me-dicine. Informed consent was obtained from the parents of children participating in this study.

\section{A standard protocol for examina- tion was followed for all patients including:}

i) History: including age, sex, age of onset of squint, history of previous treatment (glasses, occlusion therapy, or surgery), and associated symptoms.

ii) Visual acuity of both eyes separately (with \& without glasses if available). From 6 months to 1 year, the method used was fixation and follow; from 1 year to 3 years with picture cards or chart; from 3 to 6 years with E chart; from 6 years and up with Land-olt's C chart.

iii) Slit-lamp biomicroscopy of the anterior segment (For cooperative children).

iv) Fundus examination with fully dilated pupils (under general anesthesia for infants, and in a clinic for cooperative children).

v) Ocular motility examination in the 6 cardinal positions of gaze.

vi) Cover test for distance and near.

vii) Measurement of deviation in distance and near vision with Hi-rschberg test (in children below 3 years), and with prism bar (in cooperative children above 3 years).

viii) A cycloplegic refraction using cyclopentolate $1 \%$ eye drops.

ix) A record of any abnormal head posture, nystagmus, or amblyopia.

\section{Children with esotropia in this study were classified into 3 main groups:}

Group A: Congenital (Infantile) esotropia; Group B: Accommodative esotropia (which was subdivided into 3 subtypes: fully accommodative, partially accommodative, and accommodative esotropia with convergence excess); and Group C: Non-accommodative esotropia

The following parameters were accurately defined before the study: Congenital (Infantile) esotropia was defined by an onset before 6 months of age, angle $>40$ PD, cross fixation, normal neurological stat-us, and normal cycloplegic refraction 
SOHAG MEDICAL JOURNAL Clinical Variability and Treatment Outcomes of Pediatric Esotropia

for patient's age. Fully accommodative esotropia was defined as an esotropia which was totally corrected for distance and near with hypermetropic correction; partially accommodative esotropia was defined as a reduction in the angle of esotropia of $\geq 10 \mathrm{PD}$ for distance or near with hypermetropic correction, and accommodative esotropia with convergence excess was defined as esotropia with the near angle exceeded the distance angle by 15 PD while using the hypermetropic correction. Non-accommodative esotropia was defined with the angle of esotropia not changed by hypermetropic correction (glasses).

Postoperative follow up (For patients undergoing squint surgery)

Post-operative follow up was done on the $1^{\text {st }}$ day, $1^{\text {st }}$ week, $1^{\text {st }}$ month, 3 months, 6 months, and 1 year.

Surgical outcome: Patients were classified according to the surgical outcome into 2 groups based on their post-operative alignment: (1) Successful (Favorable) outcome; (2) Re-operation for either under-correction "residual esotropia" or over-correction "consecutive exotropia". A successful (Favorable) outcome was defined as final alignment wit-hin \pm 10 degrees of straight.

\section{Results}

Among all strabismus cases presented to the strabismus clinic during the period of the study, a total of 52 children with nonparalytic (concomitant) esotropia were included (27 males \& 25 females); 23 patients $(44.2 \%)$ with congenital (infantile) esotropia, 19 patients (36.5\%) with accommodative esotropia, and 10 patients (19.2\%) with non-accommodative esotropia. The age group of patients varied from 6 months to 12 years. There were 7 (13.5\%) children in 6 months to 1-year age group, $12(23.1 \%)$ in 12 years group, $4(7.7 \%)$ in $2-3$ years group, $14(26.9 \%)$ in 3-6 years group, 6 $(1.5 \%)$ in 6-8 years group, and $9(17.3 \%)$ in 8-12 years group (Table 1). The results of each of the 3 groups will be discussed separately (Table 2).

\begin{tabular}{|l|c|c|}
\hline Data & No. & \% \\
\hline Age: & & \\
6 m - 1 y & 7 & 13.5 \\
$1-2$ y & 12 & 23.1 \\
$2-3$ y & 4 & 7.7 \\
3-6 y & 14 & 26.9 \\
6-8 y & 6 & 11.5 \\
$8-12$ & 9 & 17.3 \\
\hline Sex: & & \\
Male & 27 & 51.9 \\
Female & 25 & 48.1 \\
\hline Total & $\mathbf{5 2}$ & $\mathbf{1 0 0}$ \\
\hline
\end{tabular}

Table 1. Demographic data of children with esotropia in this study

\section{Group A: congenital (infantile) esotropia (Fig. 1, 2)}

There were a total of 23 (10 males \& 13 females) cases of infantile esotropia. The age of patients at presentation ranged

\begin{tabular}{|l|c|c|}
\hline Type of esotropia & No. & \% \\
\hline (1) Congenital (Infantile) esotropia & $\mathbf{2 3}$ & $\mathbf{4 4 . 2}$ \\
\hline (2) Accommodative esotropia & $\mathbf{1 9}$ & $\mathbf{3 6 . 5}$ \\
a. Fully accommodative esotropia & 16 & 30.8 \\
b. Partially accommodative esotropia & 3 & 5.8 \\
\hline (3) Non-accommodative esotropia & $\mathbf{1 0}$ & $\mathbf{1 9 . 2}$ \\
\hline Total & $\mathbf{5 2}$ & $\mathbf{1 0 0}$ \\
\hline
\end{tabular}

Table 2. Types of esotropia in this study

from 6 months to 3 years. There were 7 (30.4\%) cases presented at the age of 6 months -1 year, $12(52.2 \%)$ at $1-2$ years, and $4(17.4 \%)$ at $2-3$ years. Cycloplegic refraction was below +3 diopters in all 
cases The preoperative angle of esotropia was $>40$ prism diopter (PD) in all cases. Inferior oblique overaction (IOOA) was seen in 5 cases ( 2 mild, 2 moderate $\&$ one severe), latent nystagmus in 3 cases, and dissociated vertical deviation (DVD) in one case. All cases were planned for early surgical correction with bilateral medial rectus recession in 19 cases, and recession of medial rectus/resection of lateral rectus in the non-dominant amblyopic eye in the remaining 4 cases.
Inferior oblique myectomy was done in one case with severe IOOA. A successful (Favorable) outcome was seen in 18 cases, and re-operation for correction of residual esotropia was done in 5 cases, with unilateral lateral rectus resection in 4 cases, and unilateral medial rectus recession in one case, 3 months after the initial surgery. Patients with preoperative amblyopia were further followed up with occlusion therapy for varying periods.

\section{Figure1. Four cases of conge- nital (Infantile) esotropia (A) Preoperative clinical photo. (B)Postoperative clinical photo. Case 3 was associated with inferior oblique overaction}

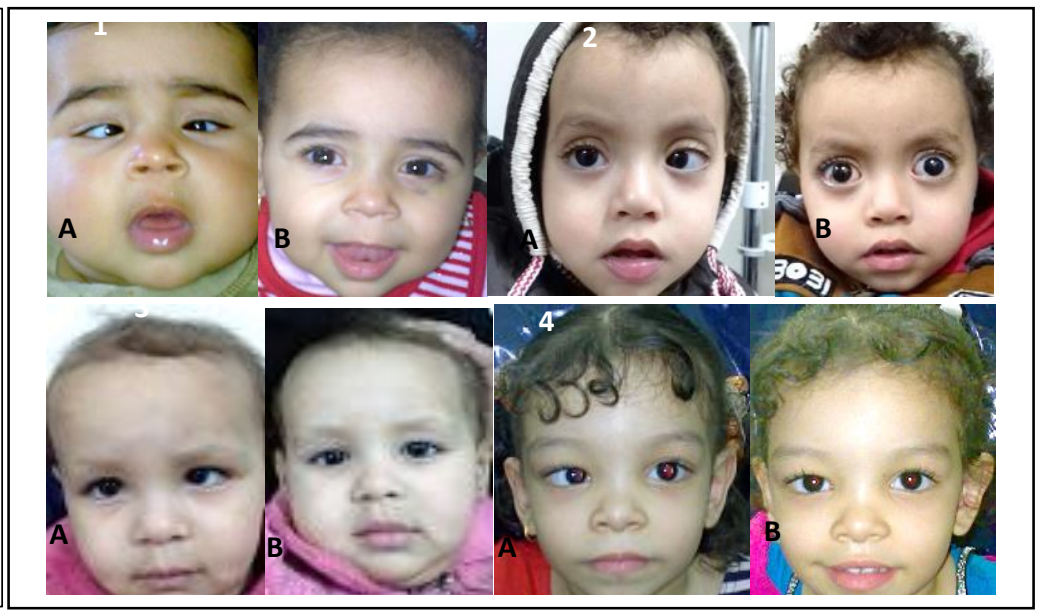


SOHAG MEDICAL JOURNAL Clinical Variability and Treatment Outcomes of Pediatric Esotropia

\section{Group B: Accommodative esotropia (Fig. 3)}

A total of 19 (11 males \& 8 females) cases of accommodative esotropia were included in this study; of whom 16 patients $(30.8 \%)$ of fully accommodative esotropia, and 3 patients $(5.8 \%)$ of partially accommodative esotropia. Cycloplegic refraction was $>+4 \mathrm{D}$ in all cases. For fully accommodative esotropia, the deviation was totally corrected for near and distance with hypermetropic correction (glasses), and no patient underwent surgery. For partially accommodative esotropia, the deviation was partially corrected with glasses, and surgery was indicated for the correction of the residual esotropia based on the angle of deviation at distance vision, while the child wearing his/her glasses). Unilateral medial rectus recession was done in one case, and unilateral medial rectus recession/lateral rectus resection in 2 cases. A successful (Favorable) outcome was seen in the 3 cases during the follow-up period after surgery.

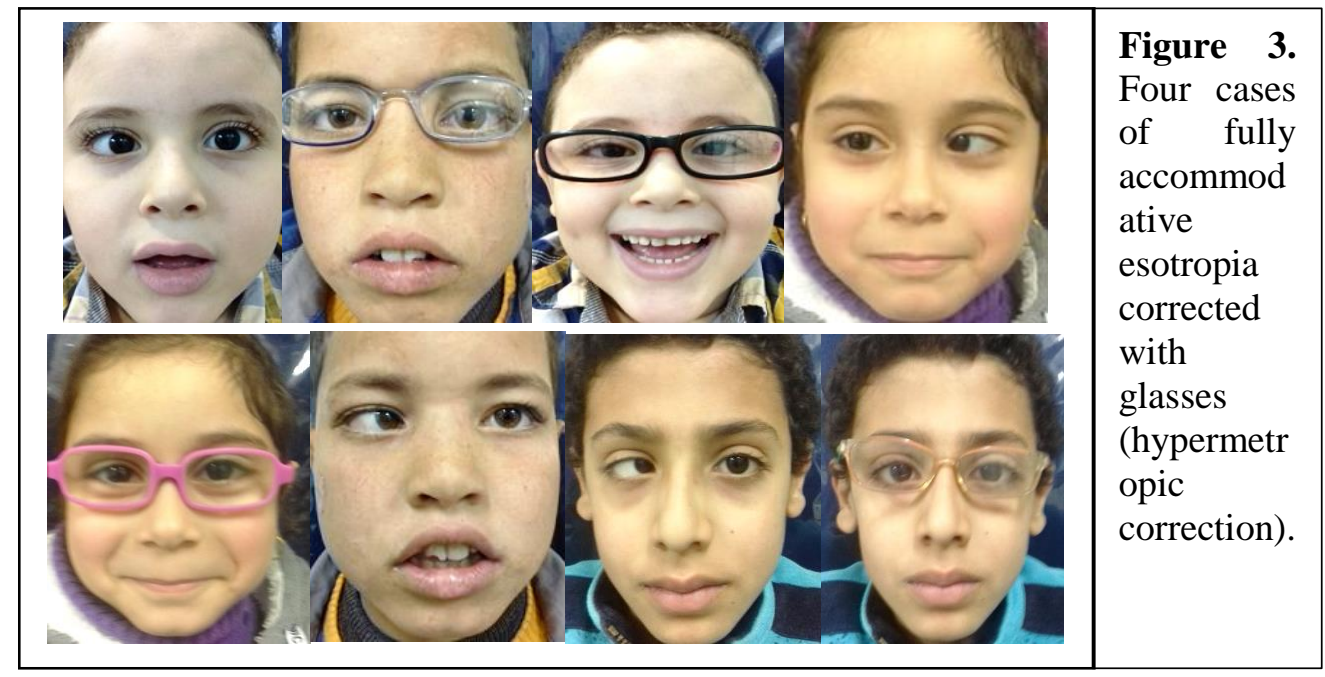

Group C: Non-accommodative esotropia (Fig. 4, 5)There were 10 children (6 males \& 4 females) with non-accommodative esotropia in this study. The mean age at presentation was 7 years (range 3 12). The mean cycloplegic refraction was $\pm 1.50 \mathrm{D}$ to \pm 2.50 . The mean esodeviation for near and distance fixation was $\pm 40 \mathrm{PD}$ (range 20-80). None had near/distance disparity. Inferior oblique overaction was present in 2 cases. Bilateral medial rectus recession was done for 7 children, a bilateral medial rectus recession with unilat- eral lateral rectus resection in 2 children, and a unilateral recession/resection in the non-dominant amblyopic eye for one child. Post-operative amblyopia treatment was required for one child. A successful (favorable) surgical outcome was achieved in 9 cases, and reoperation for correction of residual esotropia (> 10 PD) was done in one case. Treatment outcomes of pediatric esotropia are summarized in (Table 3). 
SOHAG MEDICAL JOURNAL Clinical Variability and Treatment Outcomes of Pediatric Esotropia

\begin{tabular}{|c|c|c|c|}
\hline Type of esotropia & $\begin{array}{c}\text { Type of treatment } \\
\text { (Glasses vs Surgery) } \\
\text { (No.) }\end{array}$ & $\begin{array}{c}\text { Success } \\
\text { (Favorable) } \\
\text { outcome* }^{*}\end{array}$ & $\begin{array}{c}\text { Residual angle > } \\
10 \text { PD } \\
\text { (Re-operation) }\end{array}$ \\
\hline (1) Congenital (Infantile) esotropia & Surgery (23)(All cases) & 18 & 5 \\
\hline $\begin{array}{l}\text { (2) Accommodative esotropia } \\
\text { a. Fully accommodative esotropia } \\
\text { b. Partially accommodative esotropia }\end{array}$ & $\begin{array}{l}(19) \\
\text { Glasses (16) } \\
\text { Glasses + Surgery (3) }\end{array}$ & $\begin{array}{c}16 \\
3\end{array}$ & $\begin{array}{l}\text { 0 } \\
\text { 0 }\end{array}$ \\
\hline (3) Non-accommodative esotropia & Surgery (10) & 9 & 1 \\
\hline
\end{tabular}

Table 3. Treatment outcomes of pediatric esotropia in this study

* Orthotropia or residual angle < 10 PD.

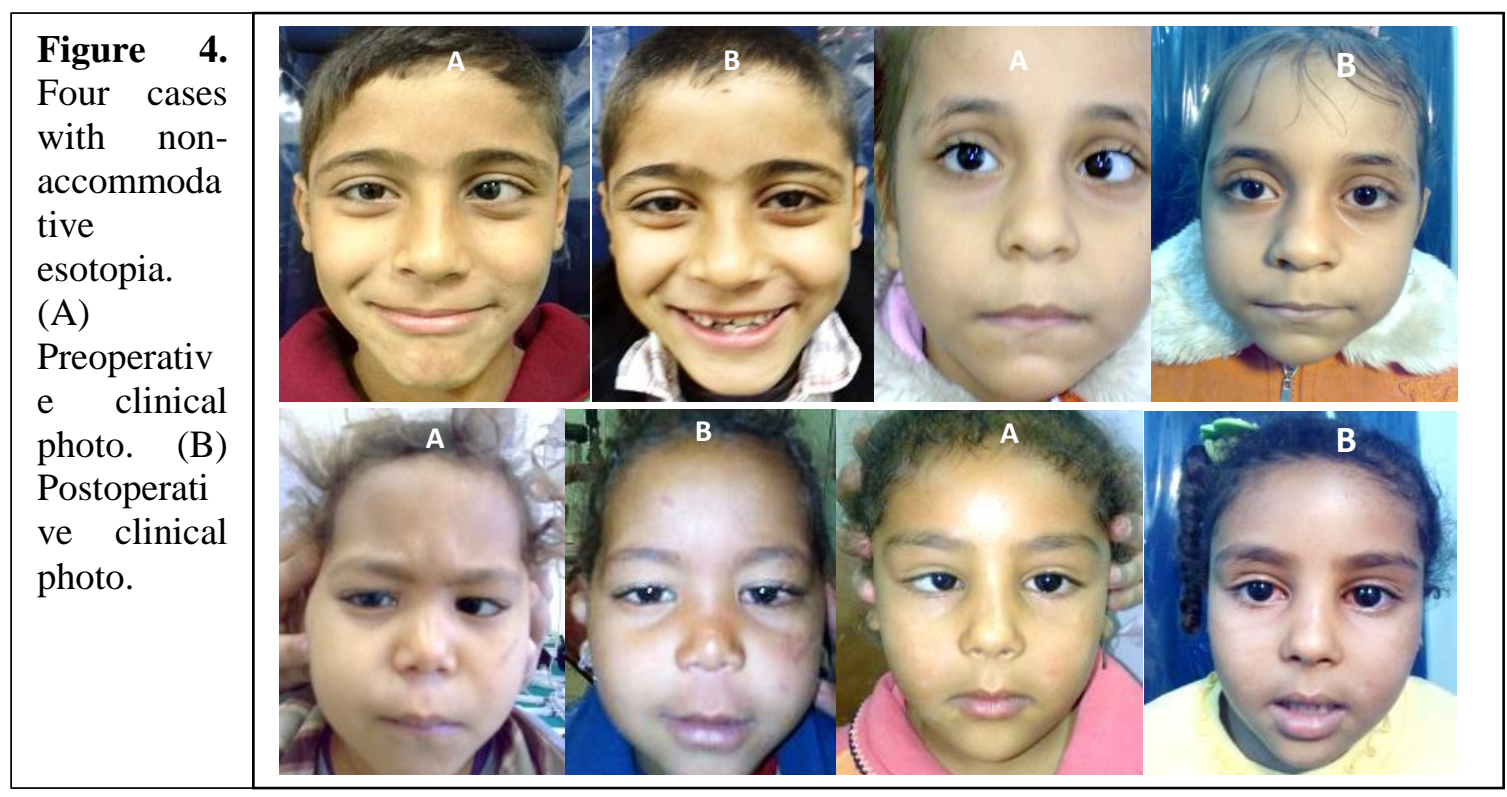

\section{Discussion}

Strabismus is a common presenting ocular problem at outpatient clinics of ophthalmology. Pediatric esotropia is the most common type of strabismus disorder presenting at the pediatric ophthalmology and strabismus clinics. Early diagnosis and treatment of pediatric strabismus are essential before brain full maturity. Apart from improving the cosmetic appearance, strabismus surgery in children helps to restore binocular vision and improve psychosocial aspects. ${ }^{12,13}$

The present study aimed to evaluate the clinical types, clinical features, and treatment outcomes of esotropia among children presented to the strabismus clinic.
For the purpose of discussion and analysis of results, among all patients with esotropia, pediatric patients aged $\leq 12$ years were included in this study. They were fully evaluated, and classified into 3 main groups namely, congenital (infantile), accommodative, and non-accommodative esotropia. The results of each group were further studied and analyzed. Infantile esotropia was the commonest type (23 patients, $44.2 \%$ ), followed by accommodative esotropia (19 patients, $36.5 \%$ ), then non-accommodative esotropia (10 patients, 19.2\%). Fully accommodative esotropia was the commonest type of accommodative esotropia group (16 patients, 30.8\%). The age of 
presentation of patients in this study ranged between 6 months and 12 years. Some patients with infantile esotropia were presented late, even beyond 2 years of age. This may be explained by the fact that parents of those children were late for seeking medical consultation due to different causes such as poor financial condition, false beliefs, or ignorance.

The age for surgery in infantile esotropia has been discussed by many authors in the literature over the last five decades. $^{14,15}$ Whether to do an early or late surgery for infantile esotropia was a matter of controversy in the literature. Some authors $^{16-18}$ had recommended $4-6$ months as the earliest age for congenital esotropia surgery; while others recommended late surgery. Many studies in the literature had been conducted to compare early versus late surgery for congenital (infantile) esotropia. ${ }^{19,20}$ However, in our study, all infantile esotropia cases were operated upon as early as 6 months and thereafter, so, this factor (early vs late surgery) could not be compared with other studies in the literature.

The success rate of surgery for pediatric esotropia in our study was $69.2 \%$ (cases of esotropia in whom squint surgery was done). The outcome of strabismus surgery, in general, have been reported in many studies in the literature, with great variability of the results ranging from $30 \%$ to $80 \%$. ${ }^{21}$ Several pre-operative, intra-operative, and postoperative factors are suggested to play a role in the final outcome of surgery such as the type of strabismus, ${ }^{22,23}$ age at strabismus surgery, ${ }^{24,25}$ pre-operative angle of deviation, ${ }^{26}$ sensory and motor outcomes, ${ }^{27}$ types of surgery and muscles operated upon, ${ }^{26,28}$ binocular vision, ${ }^{29}$ postoperative alignments, ${ }^{30}$ and surgeon's experience (residents versus consultant strabismus surgeons). ${ }^{21,32,33}$ All the previous factors are important in the final results of strabismus surgery. However, a comparison between ours and other studies may not be very accurate because of many differences in the previously mentioned factors. For example, our study was conducted on the pediatric age group (not adult strabismus), and for patients with concomitant (non-paralytic) esotropia only. Patients with paralytic esotropia, or associated with neurological disorders like cerebral palsy were excluded from our study.

Accommodative esotropia usually manifests between ages 1 and 3 years (usually after 2 years) and can be sub-classified into fully and partially accommodative types. Fully accommodative esotropia requires no surgical intervention and is treated by full hypermetropic correction (glasses) following cycloplegic refracttion. Acquired non-accommodative esotropia is a specific type of esotropia that refers to a group of esotropia patients not associated with accommodative effort. The onset of this condition may be acute, or it can result from deterioration of existing, previously controlled, esotropia. ${ }^{33}$ Several risk factors have been suggested for the decompensation of fully accommodative esotropia into acute nonaccommodative type, including the onset of esotropia before age 2 years, ${ }^{34,35}$ - oblique dysfunction, ${ }^{34}$ and a greater esodeviation at near than at distance. ${ }^{36-39}$

\section{Conclusion}

Pediatric esotropia may present at birth, during the first year of life, or acquired during early childhood. Treatment of pediatric strabismus should be initiated as early as possible to achieve binocularity, improve visual outcomes, and prevent psychosocial effects. Early surgery for infantile esotropia is recommended by the authors in this study with a successful outcome in most cases. Post-operative 
alignment within \pm 10 PD of straight was considered as a significant indicator of a successful outcome. Fully accommodative esotropia cases were totally corrected with glasses with no need for surgery. Surgery was performed in partially accommodative esotropia cases to correct the residual angle while wearing glasses.

\section{References}

1. Von Noorden GK. Binocular vision and ocular motility: Theory and management of strabismus, 5th edn. St Louis: Mosby, 1996, p. 351.

2. Akpe BA, Dawodu OA, Abadom EG. Prevalence and pattern of strabismus in primary school pupils in Benin city, Nigeria.Nigerian Journal of Ophthalmology. 2014; 221:38-43.

3. Giorgis, Abeba Tekle, and Abebe Bejiga. Prevalence of strabismus among preschool children community in Butajira Town. Ethiopian Journal of Health Development.2001; 15.2: 125-130.

4. Friedman, David S., et al. Prevalence of amblyopia and strabismus in white and African American children aged 6 through 71 months:"the Baltimore Pediatric Eye Disease Study." Ophthalmology. 2009; 116.11: 2128-2134.

5. Matsuo, Toshihiko, and Chie Matsuo. The prevalence of strabismus and amblyopia in Japanese elementary school children. Ophthalmic epidemiology. 2005; 12.1: 31-36.

6. Amer A. Relative prevalence of various types of strabismus in patients attending NGO's medical centers in Gaza Strip. Science Journal of Public Health. 2014; 1(1): 1-5.

7. Rah, Sang Hoon, Hong Sang Jun, and Soon Hyun Kim. An epidemiologic survey of strabismus among school-children in Korea. Journal of the Korean Ophthalmological Society. 1997; 38.12: 2195-2199.

8. Billson F. Concepts in strabismus. In: Billson F, editor. Strabismus Fundamentals of Clinical Opthalmology. London: BMJ Books; 2003.
9. Kothari M, Balankhe S, Gawade R, Toshnival S. Comparison of psychosocial and emotional consequences of childhood strabismus on the families from rural and urban India. Indian journal of ophthalmology. 2009; 574:285.

10. Helveston EM. Understanding, detecting, and managing strabismus. Community eye health. 2010; 2372:12.

11. Billson F. Therapy of strabismus. In: Billson F, editor. Strabismus Fundamentals of Clinical Opthalmology. 1st ed: BMJ Books; 2003. p.70.

12. Greenberg, Amy E., et al. "Incidence and types of childhood esotropia: a population-based study. Ophthalmology. 2007; 114.1: 170-174.

13. Mohney, Brian G. Common forms of childhood esotropia. Ophthalmology. 2001; 108.4: 805-809.

14. Taylor DM. How early is early surgery in the management of strabismus? Arch Ophthalmol. 1973;70: 752-756.

15. Simonsz HJ, Kolling GH, Unnebrink K. Final report of the early vs. late infantile strabismus surgery study (ELISSA), a controlled, prospective, multicenter study. Strabismus. 2005;13:169-199.

16. Von Noorden GK. A reassessment of infantile esotropia. LXIV Edward Jackson Memorial Lecture. Am J Ophthalmol. 1988;105:1-10.

17. Banks MS, Aslin RN, Letson RD. Sensitive period for the development of human binocular vision. Science. 1975;190:675-677.

18. Helveston EM. 19th annual Frank Costenbader Lecture-the origins of congenital esotropia. J Pediatr Ophthalmol Strabismus. 1993;30:215232.

19. Assaf AA. Early versus late alignment of infantile esotropia. Strabismus. 1995;3:61-69.

20. Vasseneix C, Retour A, Ducrotte D. Infantile esotropia: comparison of surgery results when the intervention takes place before or after 30 months of age. J Fr Ophthalmol. 2005;28:743-748.

21. Crouch ER Jr. A comparison of the success rates of resident and attending 
strabismus surgery. J Pediatr Ophthalmol Strabismus 1993; 30: 157-8.

22. Keenan JM, Willshaw HE. The outcome of strabismus surgery in childhood esotropia. Eye. 1993; 7, 341-345.

23. Keenan JM, Willshaw HE. The outcome of strabismus surgery in childhood exotropia. Eye. 1994; 8:632-7.

24. Simonsz HJ, Kolling GH. The best age for surgery for infantile esotropia. Eur $\mathrm{J}$ Paediatr Neurol. 2011; 15:205-8.

25. Wong AM. Timing of surgery for infantile esotropia: sensory and motor outcomes. Can J Ophthalmol. 2008; 43:643-51.

26. Forrest MP, Finnigan S, Finnigan S, Gole GA. Three horizontal muscle squint surgery for large-angle infantile esotropia. Clin Exp Ophthalmol. 2003;31:509-16.

27. Birch EE, Stager DR Sr. Long-term motor and sensory outcomes after early surgery for infantile exotropia. JAAPOS. 2006;10:409-13

28. Wang L, Nelson LB. One muscle strabismus surgery. Curr Opin Ophthalmol. 2010; 21:335-40.

29. Maruo T, Kubota N, Sakaue T, Usui C. Esotropia surgery in children: long term outcome regarding changes in binocular alignment; a study of 956 cases. Binocular Vis Strabismus. 2000, 4: 213-20.

30. Sharma AK, Thapa M, Shrestha GB, Sitaula S, and Shrestha GS. The outcome of horizontal strabismus surgery and parents' satisfaction. Nepal J Ophthalmol 2014; 6: 162-169.

31. Mehta VJ, Utz VM, Traboulsi EI, Rychwalski PJ. Outcomes of strabismus surgery with or without trainee participation as Surgeon Ophthalmology. 2014;121:2066-9.

32. Wisnicki HJ, Repka MX, Raab E, Hamad GG, Kirsch D, Nath A, Loupe DN. A comparison of the success rates of resident and attending strabismus surgery. Journal of pediatric ophthalmology and strabismus. Mar-Apr 1993;30:118-121

33. Mohney BG. Acquired nonaccommodative esotropia in childhood. J AAPOS. 2001; 5:85-89.

34. Dickey CF, Scott WE. The deterioration of accommodative esotropia: frequency, characteristics, and predictive factors. $\mathbf{J}$ Pediatr Ophthalmol Strabismus. 1988; 25:172-175. 35. Black BC. The influence of refractive error management on the natural history and treatment outcome of accommodative esotropia. Trans Am Ophthalmol Soc. 2006; 104:303-321.

36. Cakir B, Bursali O, Ozmen S, et al. Factors influencing stereopsis in patients with both refractive accommodative esotropia and amblyopia. Int Ophthalmol 2019; 39:1263- 7

37. Ludwig IH, Imberman SP, Thompson HW, Parks MM. A long-term study of accommodative

esotropia. TransAmOphthalmolSoc. 2003 ;101:155-161.

38. Ludwig IH, Parks MM, Getson PR, Kammerman LA. Rate of deterioration in accommodative esotropia correlated to the AC/A relationship. J Pediatr Ophthalmol Strabismus. 1988; 25:8-12.

39. Mulvihill A, MacCann A, Flitcroft I, O'Keefe M. Outcome in refractive accommodative esotropia. $\mathrm{Br} \quad \mathrm{J}$ Ophthalmol. 2000; 84:746-749. 